\title{
Needs analysis of national parks for applying big data solutions in tourism management
}

\author{
Yulan Yuan ${ }^{1, *}$, Chaang-Iuan Ho $^{2}$ \\ ${ }^{1}$ Department of Tourism Management, Jinwen University of Science and Technology, Taipei, Taiwan \\ ${ }^{2}$ Department of Leisure Services Management, Chaoyang University of Science and Technology, Taichung, Taiwan
}

\section{A R T I C L E I N F O}

\section{Article history:}

Received 12 February 2017

Received in revised form

1 October 2017

Accepted 2 October 2017

\section{Keywords:}

Needs analysis

Big data

National parks

Tourism management

\section{Introduction}

National Parks (NPs) serve as a mainstay of biodiversity conservation and as reservoirs of wildlife. They also house human communities, providing livelihoods and sustenance. The International Union for Conservation of Nature (IUCN) identifies the objectives of National Parks as to take steps to effectively enforce the respect of ecological, geomorphological or aesthetic features that have led to its establishment, and to allow visitors to enter sites under special conditions for inspirational, educative, cultural, and recreational purposes (Hanna et al., 2008; IUCN/WCMC, 1994).

This definition clearly indicates that NP agents hold dual missions. NP agents need to provide information services and education opportunities with limited financial and human resources to prevent the recreation conflicts and environmental impacts resulting from tourism activities (Marion and Reid, 2007). Furthermore, they need to obtain support from various groups of stakeholders in sustaining their management actions. Information is thus fundamental to the tourism management of NPs, and the capability to manage the information is vital to delivering quality service and education development.

\footnotetext{
* Corresponding Author.

Email Address: yoyo@just.edu.tw (Y. Yuan)

https://doi.org/10.21833/ijaas.2017.012.006

2313-626X/C) 2017 The Authors. Published by IASE.

This is an open access article under the CC BY-NC-ND license

(http://creativecommons.org/licenses/by-nc-nd/4.0/)
}

NPs, like other organizations, enrich their capability of reacting to changes according to their ability to adopt and use new innovation in assisting their operations. Thus, capability of using information technology (IT) for NPs is as important as conserving natural resources. The majority of NP agencies still currently rely on a small number of rangers and employees to watch over a vast amount of areas, which cover more than $6 \%$ of the world's land area in more than 150 countries (Farrell and Marion, 2001). To ensure that extensive large of land areas stay protected, NP agencies and policymakers require information on the threats and stresses that they face. They also need support from many stakeholders and visitors in sustaining their management actions. Information collection and exchange is fundamental to the tourism management of NPs.

Recent publications reveal that Big Data (BD) can address those challenges (Yuan and Ho, 2015). BD refers to things one can do at a large scale that cannot be done at a smaller one, to extract new insights or create new forms of values (MayerSchönberger and Cukier, 2013). Creating value is considered the most significant dimension of BD. The solution from BD provides the basis for optimizing management processes and mitigating risks. BD can assist NP agencies in monitoring human activities (Brown and Weber, 2013) and environmental condition (Joo et al., 2009), conserving biodiversity (Henry and Armstrong, 2004) building public-agent relationship, and sustaining visiting experience. 
BD solutions involve multiples IT components and data capability that are supported by IT (Fig. 1). From the IT perspective, it refers to the integration of IT into an organizational structure. IT integrates sensors/mobile devices, cloud computing, and IoT into the physical infrastructure of a destination (Buhalis and Amaranggana, 2013; Gretzel et al., 2015). From the data perspective, it refers to new ways of collecting and exchanging of information (Gretzel et al., 2015). Therefore, applying DB goes beyond IT adoption, involving data collection, cleaning, integration, analysis and visualization to the end users. That is, an organization needs the ability to capture and analyze data at very large scale in to successfully implement BD. Davenport (2014) defines BD as "the ability... to harness information in novel ways to produce useful insights of goods and service of significant value." Such complexity of applying BD requires extensive knowledge of BD.

\begin{tabular}{|c|c|c|c|c|c|}
\hline Cloud computing & \multicolumn{5}{|c|}{ Data Ability } \\
\hline Internet of Things & ฐิ & م & 음 & $\frac{n}{n}$ & 들 \\
\hline $\begin{array}{l}\text { End-user Internet } \\
\text { Service System }\end{array}$ & $\bar{\rho}$ & $\stackrel{\mathscr{U}}{U}$ & 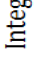 & 䒕 & $\stackrel{\frac{\pi}{5}}{5}$ \\
\hline
\end{tabular}

Fig. 1: The IT components and data ability of big data

The technology implementation is determined by users perceiving the features of technology in matching the practical needs of their organizations (Rogers, 2003; Yuan et al., 2006). Whether NP agents apply a BD solution depends mainly on how BD is perceived as consistent with needs of the missions and goals of NPs. Additionally, the aims and nature of the organizations often affect implementation failure and resentment of adopting innovations (Yuan et al., 2006). That is, needs are context-specific and organizational task oriented. Practical needs can be classified as needs of organization, data, and technology, as given in the above definition of BD. Those needs vary by organization. Therefore, analysis of such needs in the context of NP can provide insights to the NP agents guiding them in big data adoption and implementation.

\section{Methodology}

The methodology of this study was inspired by technology user case scenarios proposed by Zillner and Neururer (2015), and Attenberg et al. (2011). This study comprises of two stages: literature review and interview. In the first stage, two groups of literatures are reviewed, namely tourism management of NPs, and the use case scenarios of big data.

This study is exploratory in the sense that needs are identified from literature review. Needs can be classified as: known, known-unknown, and unknown A crucial fact for matching the practical needs and technology features is that users often do not know the technology well enough to comprehend all of its potentials. Restated, users don't know what they don't know (Attenberg et al., 2011). Additionally, NP agents might not recognize their tourism management needs. Use case scenarios gathered via literature review could thus be employed to obtain known-unknown needs, and also provided bases for discovering unknown-unknown needs.

Researchers have identified five classes of known needs of tourism management (Ali and Frew, 2013; Hammit et al., 2000):

1. Carrying capacity (CC) of NPs: To prevent the environmental degradation resulting from excessive number of visitors. To identify the usage and visitation by visitor counting. Carrying capacity is thus defined in terms of two interrelated dimensions, "where" and "who". "Where" refers to the characteristics of the locality, which determine the resilience to human activities. The characteristics of locality include the type of resources, and the vulnerability and sensibility of local ecosystems and cultural heritage. "Who" refers to the characteristics of visitor behavior, which can be expressed in terms of the number of visitors, the frequency and length of visits, the motives for visiting, the type of activities in which visitors engage, and the type of mobility, visitor flows and spatial patterns of concentration/dispersion within a protected area.

2. Monitoring (M): To provide information about changes in wildlife habitat and use by humans for policy-making and management action.

3. Environmental education and interpretation (EEI): To apply education programs and information strategies to motivate visitors taking low impact behavior as interacting with tourism sites of NP. Tourism management of NP strongly emphasizes on the importance of interpretation. Visitors need interpretation to learn the behavior codes of low impact behavior and also leverage their knowledge of NP.

4. Marketing and information services (MIS): The marketing effort is to attract the type of visitors who enjoy sustainable tourism, or to dissuade potential visitors from visiting a tourism site.

5. Public involvement (PI): Environmental resource management is the management of the interaction with and impact of visitors and stakeholders on the environment to help protect and maintain ecosystem services for future generations.

The knowledge of the needs of NP tourism management was applied to develop the interview questions.

In the second stage, interviews were guided by eight open questions with two aims: (1) to inquire of specific big data needs, and (2) to discuss the 12 use case scenarios with interviewees to elicit the unknown-unknown needs. The 12 use case scenarios are as follows: (1) trip planning and recommendation; (2) monitoring the spatial distribution and flow of tourists; (3) analyzing destination images; (4) monitoring the satisfaction of tourists; (5) forecasting the number of visits; (6) predicting the occupancy rate of accommodation; (7) 
monitoring and controlling traffic conditions; (8) public participation; (9) emergency rescue system; (10) warning systems; (11) measuring natural resources, and (12) citizen science.

A pilot study of an NP, which initiated a BD project, was interviewed to develop an interview protocol or format that contained quantifiable measures, and possessed construct and content validity as well as reliability. Three researchers experienced in qualitative research worked together to assure the reliability of the interview results. Construct validity was achieved by developing an interview format with the assistance of researchers doing similar research on content validity and rationale of research questions. In addition, the interview format was assured by thoroughly discussing with two managerial personnel of the NPs.

A few NPs have adopted a BD solution, or recently started BD projects. Therefore, a snowball sampling approach was adopted. Various levels of staffs from three NPs were interviewed to discover their big data requirements in tourism management. The interviewees (Table 1) were selected because they were directly responsible for big data initiation or performing related projects. Each interview was recorded and transcribed. Each interviewee was interviewed more than once. Any new requirement that emerged during the interview, and had not been identified in either literature review nor use case scenarios, was written as a new use case scenario, and then considered for a second round interview. This step was taken repeatedly until no further use case scenario emerged.

Table 1: The list of interviewees

\begin{tabular}{cc}
\hline Code & Occupancy \\
\hline P1 & Project managers \\
P2 & Director, Provincial Bureau of Tourism in an UNESCO \\
T1 & site \\
T2 & Chief, National Parks Division \\
T3 & Headquarters \\
U1 & Chief, Resource Information Services Division, National \\
U2 & Park Service \\
U3 & Data manager, Ministry of the Interior \\
\hline
\end{tabular}

\section{Big data needs of national parks in tourism management}

Tables 2, 3, and 4 present the practical needs of NP agencies that expect that BD would be able to provide solutions. Table 2 identifies ten known needs of tourism management were identified, namely, (1) to monitor visitor flow and distribution; (2) to prevent illegal recreational usages; (3) to ease traffic condition; (4) to prevent poaching and other illegal activities; (5) to increase environmental awareness; (6) to aid interpretation staff tasks; (7) to assist risk management; (8) to marketing and demarketing; (9) to collect public opinions and complaints, and (10) to shape planning and policy formation. All of these are organizational needs, which reflect the existing tasks and responsibilities of NPs.
Many tourists visit an NP situated in a constantly moving upward plate and mountainous environment for mountain climbing and splendid landscape. Thus, interviewees from $\mathrm{T}$ prioritized the significance of risk management, involving searching and rescuing tourists who get lost in mountains. The rapidly growing number of tourists also requires NP agents to monitor visitor flow and distribution to prevent traffic congestion and recreation conflicts.

Interviewees from $\mathrm{P}$ with memory of a severe earthquake also emphasized the importance of risk management. They brought up the shortage of human resource in managing the vast amount of land area. Therefore, they installed surveillance sensors in the most populated area to monitor tourist flow and behavior. Tourists can report an incident and ask for help when they need. Agents from P adopted the information accumulated from sensors, specifically videos, to investigate the demographic profile of visitors, and to develop future environmental campaign and revise park creation programs.

Since the public is often not aware of the boundaries of NPs, which often locate close to human settlements, would like to use BD to prevent trespass and unlawful recreational usages, such as tourists entering parks without paying. BD was also identified as a potential solution to control illegal activities, such as illegal logging, mining, and quarrying.

Few interviewees were aware that BD could help involve the public for scientific projects, such as monitoring bird migration or integrity of habitat.

The discussion of use case scenarios further revealed known-unknown needs, which as expected were technology-related needs (Table 3). Interviewees perceived technology as a foundation for to apply BD solution, but lacked knowledge of what technology they could use and how to use it. Those technology-related needs include user applications and where to set up sensors for monitoring tourists. This suggests that interviewees were aware of potentials of applying BD, but did not know how to implement the solutions. Additionally, privacy and security was also identified as a fundamental need that should be resolved.

The U Agents realized the significance of data quality and governance, and developed data governance policy, open data policy, metadata policy and implementation guides to govern data sharing across various divisions and agencies. Their foresights provide additional use scenarios for the second round discussion. During the second round of discussion, interviewees from $\mathrm{P}$ and $\mathrm{T}$ agents began to realize that they needed to do additional before they could achieve the promises presented by BD. Table 4 presents the four data needs identified in the discussion. These are (1) data availability and quality, (2) data integration, (3) data storage, and (4) privacy and security. The users did not know where the existing available data was; or they did not know the type of data they needed, or they had little understanding of data quality. Few of them knew 
they had data and still needed more data; while many struggled to integrate the data that they already had. Thus, the users need data governance and policy, mostly do not have these as determined by the interviews. Restated, applying BD requires coordinated efforts across all divisions to synchronize and integrate the data.

Table 2: Identified known needs of Big Data

\begin{tabular}{|c|c|c|}
\hline DTM & Big Data Needs & Description \\
\hline \multirow{3}{*}{$\mathrm{CC}$} & To monitor visitor flow and & To lower the recreation conflicts and reduce the heavy use to certain areas \\
\hline & Unlawful recreational usages & To prevent nonpaying tourists from entering the park \\
\hline & Traffic condition & To ease traffic congestion and improving air quality \\
\hline M & Poaching/ Illegal activities & To control illegal activities, such as logging, mining, and quarrying \\
\hline \multirow{2}{*}{ EEI } & Environmental awareness & $\begin{array}{l}\text { To understand the effectiveness and satisfaction of mobile interpretations } \\
\text { To reach younger generations }\end{array}$ \\
\hline & $\begin{array}{c}\text { Assistance of interpretation and staff } \\
\text { tasks }\end{array}$ & To overcome the seasonal shortage of interpreters \\
\hline \multirow{3}{*}{ MIS } & Risk management & $\begin{array}{l}\text { To provide emergency help to tourists } \\
\text { To track mountain rescuer positions }\end{array}$ \\
\hline & Marketing/Demarketing & To promote the value of national parks \\
\hline & Public opinions/Complaints & $\begin{array}{l}\text { To answer to tourist questions, and respond to their complaints effectively } \\
\text { and promptly }\end{array}$ \\
\hline PI & Planning and policy formation & $\begin{array}{l}\text { To involve the public in protecting NPs } \\
\text { To involve the public in the decision process } \\
\text { To hear voices from different groups }\end{array}$ \\
\hline
\end{tabular}

Table 3: Identified known-unknown needs of Big Data

\begin{tabular}{cc}
\hline Data & Privacy/security \\
\hline Technology & User applications \\
& The location and type of sensors \\
Table 4: & Identified unknown needs of Big Data \\
\cline { 2 - 2 } Data & Data availability and quality \\
& $\begin{array}{c}\text { Data Integration } \\
\text { Storage }\end{array}$ \\
Unified data format
\end{tabular}

\section{Questions in applying big data}

This study further found that incorporating BD into organizational fabric is a complex issue, which goes beyond simply technology adoption, data storage and software installation. Such complexity makes nearly half of interviewees hastate to initiate any BD project. The main causes of the hesitation of initiating BD projects were: (1) unclear goals and objectives; (2) lack of human resources and expertise to handle mining and analysis method and system management of $\mathrm{BD}$; (3) lack of clarity the type of data and information needed to resolve problems, and (4) lack of existing data available for performing BD analysis. These reasons were also identified by Malik (2013) and Kshetri (2014).

Therefore, agents need to address four fundamental questions prior to adopting BD (Lake and Drake, 2014). First, do NP agents know about the purpose of collecting the data clearly? Second, do NP agents know whether data exists? Third, do NP agents know the way to collect data? Fourth, are they willing to explore the potential applications? NP agencies must know why NPs need to accumulate the data. NPs must be clear about their mission and tasks. The BD solution is driven simply by the problem that the NPs intend to solve. BD can leverage many organizational tasks, such as marketing and segmentation, visitor recreation behavior, information search behaviors and needs, customer relationships and services, risk management and resources management. However, the nature of an organization frames the context for technology implementation. The mission of an origination guides its operational policies and activities. An organization needs to align its technology strategies with its mission, and develop the solution accordingly. An organization that does not clearly knowing its mission and goals is unlikely to benefit from the effort of BD implementation.

To lay a solid foundation for implementing BD, NPs should consider existing internal and external data sources before introducing new methods of collecting data. This question attempts to identify existing and potential sources of data, and is often linked to the type of data. The third questions addresses how to collected and organize data that are identified as not available.

\section{Conclusion}

Undoubtedly, BD can open new horizons for assisting tourism management of NP. Tourist visits to NPs can be a strong positive force - increasing a sense of stewardship and revenues, both of which are vital for the long-term protection of those precious areas. However, the increase in visits requires NP agents to carefully plan manage and monitor tourism to mitigate any negative impacts from it, and to fulfill long-term sustainability. Interviewees recognized that BD offers substantial potential value for aiding NP tourism management. Although NP agents were very interested in using $\mathrm{BD}$, its adoption and implementation is not a straightforward task. Analytical results demonstrate that have made limited efforts to understand BD. Very few NP agents have any BD management strategy, and many of them do not know how to implement big data solutions. A few of them are just beginning to incorporate $\mathrm{BD}$ into their tourism management with aim of improving their understanding of the tourism demands and trends, 
and make higher quality decisions. However, few NP agents were beginning to adopt BD to harness its many benefits, as BD also has many technical challenges that require substantial investment. Most interviewees stated that their organizations still accumulated data collected in different formats from various sources, and thus has not yet established data standards. Further research should take a systematic approach to aligning needs with technological solutions, and develop a framework is also needed to guide NP agents through the BD implementation process.

\section{Acknowledgment}

The authors would like to thank the Ministry of Science Technology of the Republic of China, Taiwan, for financially supporting this research under Contract No. MOST 105-2410-H-228-002.

\section{References}

Ali A and Frew AJ (2013). Information and communication technologies for sustainable tourism. Routledge, Abingdon, UK.

Attenberg J, Ipeirotis PG, and Provost FJ (2011). Beat the machine: Challenging workers to find the unknown unknowns. Human Computation, 11(11): 2-7.

Brown G and Weber D (2013). Using public participation GIS (PPGIS) on the Geoweb to monitor tourism development preferences. Journal of Sustainable Tourism, 21(2): 192-211.

Buhalis D and Amaranggana A (2013). Smart tourism destinations. In: Xiang Z and Tussyadiah I (Eds.), Information and Communication Technologies in Tourism 2014: 553- 564 Springer, Cham. https://doi.org/10.1007/978-3-319-03973$2 \_40$

Davenport T (2014). Big data at work: dispelling the myths, uncovering the opportunities: Harvard Business Review Press, Boston, UK.

Farrell TA and Marion JL (2001). Identifying and assessing ecotourism visitor impacts at eight protected areas in Costa Rica and Belize. Environmental Conservation, 28(03): 215 225 .

Gretzel U, Sigala M, Xiang Z, and Koo C (2015). Smart tourism: Foundations and developments. Electronic Markets, 25(3): 179-188.
Hammit WE and Schneider IE (2000). Trends in outdoor recreation, leisure and tourism.. In: Gartner WC and Lime DW (Eds.), Recreation conflict management: 347-364. CAB International Publishing, Wallingford, UK. http://dx.doi.org/10.1079/9780851994031.0347

Hanna KS, Clark DA, and Slocombe DS (2008). Transforming parks and protected areas: Policy and governance in a changing world. Routledge, Abingdon, UK.

Henry M and Armstrong L (2004). Mapping the future of America's national parks: Stewardship through geographic information systems. ESRI Press, Redlands, USA.

IUCN/WCMC (1994). Guidelines for protected area management categories. International Union for Conservation of Nature and World Conservation Monitoring Center, Gland, Switzerland.

Joo J, Yim J, and Lee C-K (2009). Protecting cultural heritage tourism sites with the ubiquitous sensor network. Journal of Sustainable Tourism, 17(3): 397-406.

Kshetri N (2014). The emerging role of big data in key development issues: Opportunities, challenges, and concerns. Big Data and Society, 1(2): 1-20.

Lake P and Drake R (2014). Information systems management in the big data era. Springer International Publishing, Bern, Switzerland.

Malik P (2013). Governing big data: Principles and practices. IBM Journal of Research and Development, 57(3/4): 1:13.

Marion JL and Reid SE (2007). Minimising visitor impacts to protected areas: The efficacy of low impact education programmes. Journal of Sustainable Tourism, 15(1): 5-27.

Mayer-Schönberger V and Cukier K (2013). Big data: A revolution that will transform how we live, work, and think. Houghton Mifflin Harcourt, Boston, New York, USA.

Rogers EM (2003). Diffusion of innovations. The Free Press, New York, USA.

Yuan YL and Ho CI (2015). Rethinking the destination marketing organization management in the big data era. In the conference on ASE Big Data and Social Informatics, ACM, Kaohsiung, Taiwan. https://doi.org/10.1145/2818869. 2818904

Yuan YL, Gretzel U, and Fesenmaier DR (2006). The role of information technology use in American convention and visitors bureaus. Tourism Management, 27(2): 326-341.

Zillner S and Neururer S (2015). Technology roadmap development for big data healthcare applications. KIKünstliche Intelligenz, 29(2): 131-141. 